\title{
The Environmental Worldviews and Climate Change Mitigation Behaviors: Testing the New Ecological Scale in the Smallest Space Analysis for Chinese Samples
}

\author{
Wen Xue and Shouying Zhao
}

\begin{abstract}
An online survey assessing the associations between people's environmental worldviews and proenvironmental behaviors was conducted through the Qualtrics panel with 515 Mandarin-speaking residents from major Chinese cities. The Smallest Space Analysis (SSA) was adopted to test the validation of the New Ecological Paradigm (NEP) sub-dimensions generated by the factor analysis through the HUDAP (Hebrew University Data Analysis Package) software. 20 items of judging people's mitigation behavior on climate change were treated as external variables to investigate their associations with environmental worldviews in this configuration produced by the NEP scale. Results indicated that the 2 dimension solution of the NEP scale is suggested by the exploratory factor analysis, but the 3 dimension solution is valid by the SSA. For the Chinese sample, all climate change mitigation behavior variables are located in the same region of the SSA plot, which is made by items of dimension ecocentrism.
\end{abstract}

Index Terms-Worldview, NEP scale, climate change, proenvironmental behavior.

\section{INTRODUCTION}

People's value on environmental problem has interested environmental researchers since late 1960s in United States [1]. Although no established instrument of environmental concern has been recognized as a standard in the environmental field [2], measurements assessing personal environmental value or worldview has been developed and widely tested in American sample.

However, even some environmental problems are the global issues, (e.g., climate change) it has only continued to be highly concerned in developed countries [3]. Less study has been conducted in Asian countries, such as China, which contains the largest population and also heavily polluted by high-speed population growth and industrialization. Although in China climate change communication is comparatively common compared with other Asian countries, and the government also enacted policy of dealing with national climate change, relatively few Chinese people have known about how to respond to climate changes [4];

Manuscript received July 10, 2014; revised October 15, 2014.

Wen Xue is with School of Behavioral, Cognitive and Social Sciences, University of New England, Armidale, Australia (e-mail: wxue@une.edu.au).

Shouying Zhao is with School of Education Science, Guizhou Normal University, Guiyang, China (e-mail: zhaoshouying@126.com).
On the other side, whereas the study of environmental worldview and pro-environmental behaviors has been interested by researchers in Western country, relatively a few studies have been conducted in China and other Asian developing countries [5], [6]. At present, there is no validate study developing measurement for Chinese citizens' environmental worldviews and also tested whether it can perceive Chinese people's environmental adaptive behavior in the same way as their Western counterparts.

The aim of current study was to develop a new measure to assess Chinese environmental worldviews in the Smallest Space Analysis approach (SSA), and determine how these worldviews may influence people's environmental responses, especially their personal pro-environmental behavior.

\section{A. Environmental Worldviews}

Environmental worldviews are the values or judgments relevant to the "circumstances in which individuals and groups" are affected and can enact behaviors [7]. The main measures have been used to assess environmental worldviews is Dunlap and Van Liere's [8] NEP [9] scale. The purpose of the NEP scale is to assess individual's beliefs of the relationship between human beings and the nature [2]. The original version of the scale, called the New Environmental Paradigm, contains three dimensions: (1) 'the fragility of nature's balance', (2) 'limits to growth', and (3) 'human dominance over the nature'. Later, a revised version of the scale, which is called the New Ecological Paradigm, was proposed to replace the original one. It is expanded to 15 items, assessing not only the three original dimensions in the original version, but also as two additional ones: the 'possibility of an eco-crisis' and the 'rejection of exemptionalism'.

Most studies have considered the NEP scale as a unidimensional measure approach for last 20 years, even though some of them have found the presence of a multidimensional structure in the whole scale through the factor analysis [10], [11]. The uni-dimensional approach has the advantage of simplicity, but there are important limitations associated with this approach [12]. For example, overall predictive power of the single uni-dimensional scale may be less than for a combination of several NEP subscales. In addition, the uni-dimensional approach does not enable researchers to investigate the relative predictive power of the specific subscales.

\section{B. The Small Space Analysis}

In current study, we applied the SSA approach to examine the structure of environmental worldview measure, and also tested the associations between those climate change 
mitigation behaviors and environmental worldviews as validation analyses. SSA is an approach derived from the Facet Theory (FA) [13]. It is a multidimensional scaling technique, which maps the location of each item in a multidimensional space. It depicts each variable as a point in this space, and each point's location is determined by its distances from other variables. The higher the correlation or the more similar between two variables, the distance between them are shorter in this space [13]. SSA can provide two informal indicators to judge the quality of the configuration [14]: The first one is the coefficient of alienation, which reflects how the proposed dimension solution fits for the data (values of this index range from 0 (best) to 1 (worst). Another is the separation index, which is aim to examine the fit between the spatial solution constructed in the confirmatory SSA fits for the hypothesis. It has a range from 0 to 1 also, while value one means model fits the hypothesis perfectly [14].

\section{METHOD}

\section{A. Participants and Procedure}

The sample consisted of 515 Mandarin speakers residing in Beijing China. Respondents were members of a Qualtrics online panel, and were aged from 18-75 years, in which $87 \%$ are aged from 18 to 64 , and $13 \%$ aged more than 65 . Just under half of the respondents were female $(48 \%)$. According to Chinese census report (2011), the sample is closely comparable to percentages of individuals (aged over 15 years) in both age and gender groups within the general population (age: $89 \%$ and $11 \%$ respectively; gender: $48.7 \%$ is female; 6th National Population Census of the People's Republic of China, 2011). For the education level, 20\% participants completed high school education (Year 12) and $66 \%$ completed at least college education. Respondents with at least college education are much higher compared with the result in 2011 national statistics, which show less than $10 \%$ of Chinese has completed college education at that time (2011).This distribution indicated that most Chinese respondents involved in the Qualtrics survey panel, are with higher education level.

\section{B. Back Translation and Pilot Tested}

We followed the procedures outlined in Harkness and Schoua-glusberg's [15] report. Firstly, all measures used in the study were initially translated into Chinese (Mandarin) by the first author. The survey was then back-translated into English by the second author to ensure they matched the original scales. The back translation version will be compared with the original version. According to Harkness and Schoua-glusberg [15], the more similarities between the original version and back-translated version, the more equivalence of the Chinese questionnaire and the original English questionnaire are considered to be. In conclusion, only less than $5 \%$ content differences were found in the Chinese version and original questionnaire, which was discussed and revised before the formal test. Prior to being administered in China, the survey was pilot tested 16 native Mandarin speakers attending the University of New England.

\section{Measures}

The questionnaire contains 3 sections:

1) People's general background information, such as gender, age, etc.

2) New ecological paradigm (revised NEP). The revised NEP [9] contains 15 items of five original facets hypothesized by Dunlap [9]: balance of nature, ecocrisis, rejection of exemptionalism, limits to growth, and anti-anthropocentrism, to assess people's environmental worldviews. The scale consists of both positively and negatively worded items, all assessed on a 5-point Likert scale ( $1=$ strong disagree, $5=$ strongly agree). NEP items are presented in Table I, along with subscale factor loadings and internal consistencies.

3) Climate change mitigation behaviors were assessed using a 20-item carbon footprint scale developed by Reser et al. [16]. Respondents indicated how often ( $1=$ never, $4=$ most of the time) they engaged in a range of behaviors associated with reduced carbon emissions (e.g., Use compact florescent light bulbs, reduce air travel, purchase energy efficient appliances, etc). Cronbach's $\alpha$ was .89 .

\section{RESULTS}

\section{A. Factor Analysis for the NEP Scale}

The alpha for the Chinese version of NEP scale before deleting any items was .77, indicating an acceptable level of internal consistency [17]. An EFA was conducted through principal-axis factoring in SPSS (Version 20). To determine the number of factors to retain, we applied both scree plot and Kaiser's [18] eigenvalues-greater than-one rule for the unrotated solution. In the initial report of EFA for the NEP scale, 4 components have eigenvalues more than 1 . This is similar to Wu's [6] study, in which also 4 factors were found in the factor analysis. The KMO value of current study is $.79, p<.001$, and total explained $48.8 \%$ variance. However, the scree plot indicated that a 2 -factor solution. Solutions between 2 and 4 factors were then subjected to direct oblimin rotations $(\Delta=0)$ and assessed for interpretability. A 2-factor solution with 2 meaningful factors was judged to be most interpretable (Table I). This solution accounted for $31.5 \%$ of the total variance in the NEP scale items. Specifically, factor 1 consists of all three items in anti-anthropocentrism dimension in the original NEP scale, and two items of the rejection of exemptionalism dimension, which can be considered as the special case of anti-anthropocentrism. One balance-of-nature item and one limits-to-growth item are also located in this factor. So this factor should be named as anti-anthropocentrism. Factor 2 is highly related to the value of the balance of nature. It contains all two items in the balance of nature dimension, two items of dimension limits to growth, and all three ecocrisis items, which can be considered as the consequence of disturbing the balance of nature. This 2- factor solution can be related to two common worldviews found through the literature review. The first one is New Environmental Paradigm, which is focus on the serious ecological problems; and the other is Dominant Social Paradigm, which is talking about human' interests, and faith that science and technology 
can be effectively applied to overcome ecological limits [19], [20].

\section{B. Confirmatory SSA for the NEP Scale}

To test the validation of the EFA solution, a confirmatory smallest space analysis was conducted through the HUDAP (Hebrew University Data Analysis Package) software. The SSA plot is shown in Fig. 1. The obtained pattern of the dimensions generated by the EFA in the NEP scale reflects a clear axial structure with two partitions (separation index = 1). The perspective facet divides the map into two regions: The left partition includes all the items regarding whether the respondents holding a value of rejecting anthropocentrism, whereas items located in the right region are all associated with the perceptions of eco-centrism. Both the right and left partition constructed a configuration, which is our new NEP model of the Chinese sample.

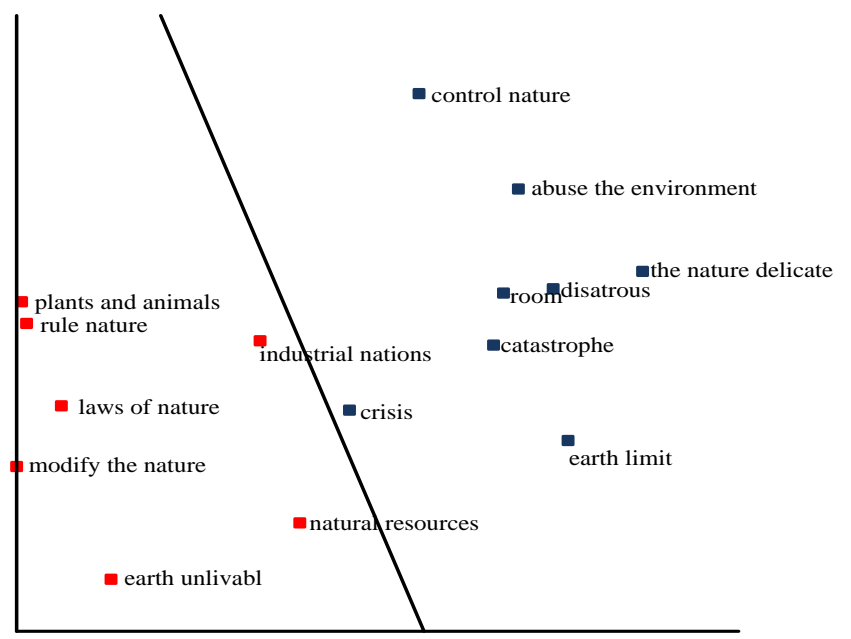

Fig. 1. The Smallest Space Analysis plot for the NEP scale.

TABLE I: FACTOR PATTERN MATRIX

\begin{tabular}{ccc}
\hline \hline & \multicolumn{3}{c}{ Pattern Matrix $^{\mathrm{a}}$ Factor } \\
\cline { 2 - 3 } & \multicolumn{2}{c}{2} \\
\hline balance2 & .701 & \\
eco3 & .663 & -.138 \\
balance1 & .555 & \\
eco1 & .546 & \\
limit3 & .541 & .286 \\
limit1 & .494 & .659 \\
eco2 & .418 & .645 \\
reject1 & .389 & .635 \\
reject3 & & .498 \\
anti3 & & .442 \\
anti2 & & .392 \\
anti1 & & .348 \\
reject2 & .322 & \\
balance3 & .241 & \\
limit2 & iterations required.
\end{tabular}

\section{The Relations between Environmental Worldviews and Pro-Environmental Behavior}

In case to test the validation of the new NEP model, the 20 items referred to the climate change mitigation behaviors were served as external variables and added to the spatial configuration of environmental worldviews through the HUDAP software. Their locations are depicted in the environmental worldviews model (see Fig. 2), which is determined by their correlation coefficients with all NEP items. It is unexpected that all those 20 mitigation behavior variables are depicted in the same region in the figure (see the cross points in the eco-centrism partition). Most of items are highly related to items assessing people's value of ecocrisis or catastrophe. This indicates that people who are highly concerned on the environmental hazard are more possibly engage in pro-environmental behaviors. However, none of them is located in the anti-anthropocentrism part, which may suggest that even people reject the view that human being should not domain the nature. They may not alternatively seek pro-environmental behaviors to reduce the natural hazards.

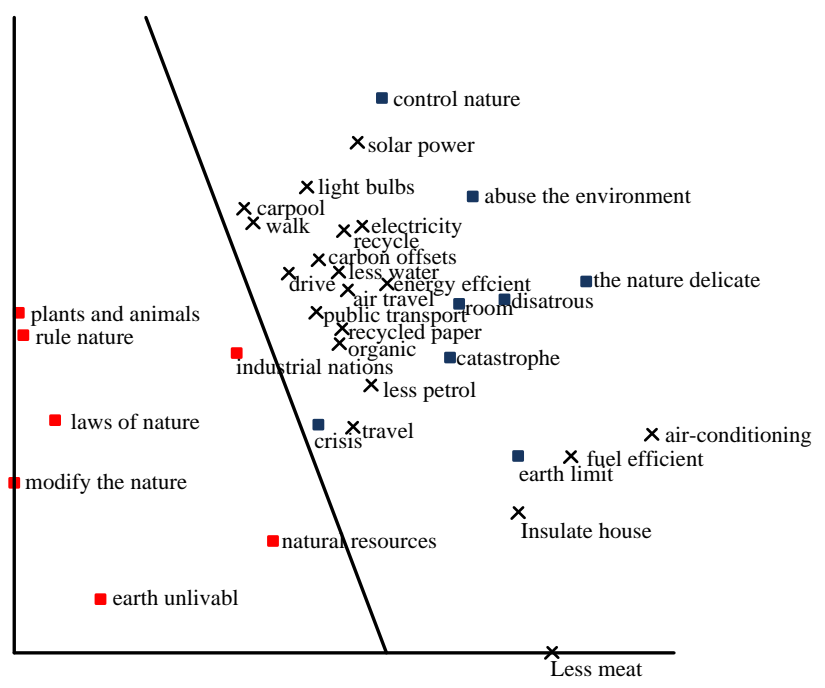

Fig. 2. The distribution of climate change mitigation behaviors in the NEP plot.

\section{CONCLUSIONS}

In Summary, the Chinese version of the NEP scale was developed and validated for measuring people's general environmental worldview. This measure contains following important strengths: (a) it is specifically suitable for Chinese sample; (b) it can be applied as two-subscale formats, from which future researchers can determine what either subdimension play a role in predicting other relevant dependent variables. Given these strengths, we believe that the Chinese version of the NEP scale will be a useful tool for researchers in this area who want to underlie the associations of environment worldview and pro-environmental behaviors.

\section{REFERENCES}

[1] A. Bostrom, R. Barke, R. M. R. Turaga, and R. E. O'Connor, "Environmental Concerns and the New Environmental Paradigm in Bulgaria," The Journal of Environmental Education, vol. 37, no. 3, pp. 25-40, Spring 2006.

[2] J. W. Amburgey and D. B. Thoman, "Dimensionality of the new ecological paradigm: Issues of factor structure and measurement," Environment and Behavior, vol. 44, no. 2, pp. 235-256, March 2012.

[3] M. Bonnes, P. Passafaro, and G. Carrus, "The ambivalence of attitudes toward urban green areas: between proenvironmental worldviews and daily residential experience," Environment and Behavior, vol. 43, no. 2, pp. 207-232, March 2011.

[4] T. Copsey, L. Hoijtink, X. Shi, and S. Whitehead, How the People of China Live with Climate Change and What Communication Can Do, Broadcasting House, Portland Place, London W1A 1AA, Wilson, UK Department for International Development (DFID), 2013, pp. 1-61.

[5] S. S. Chung and C. S. Poon, "A comparison of waste-reduction practices and new environmental paradigm of rural and urban Chinese citizens," J. Environ. Manage., vol. 62, no. 1, pp. 3-19, May 2001. 
[6] L. Wu, "Exploring the new ecological paradigm scale for gauging children's environmental attitudes in China," The Journal of Environmental Education, vol. 43, no. 2, pp. 107-120, January 2012.

[7] D. Stokols, "The paradox of environmental psychology," American Psychologist, vol. 50, pp. 821-837, October 1995.

[8] R. E. Dunlap and K. D. Van Liere, "The new ecological paradigm," Journal of Environmental Education, vol. 9, no. 4, pp. 10-19,1978

[9] R. E. Dunlap, K. D. Van Liere, A. G. Mertig, and R. E. Jones, "Measuring endorsement of the new ecological paradigm: A revised NEP scale," Journal of Social Issues, vol. 56, no. 3, pp. 425-442, December 2000.

[10] R. B. Bechtel and V. C. Verdugo, "Environmental Belief Systems: United States, Brazil, and Mexico," Journal of Cross-Cultural Psychology, vol. 30, no. 1, pp. 122-128, January 1999.

[11] L. J. Hawcroft and T. L Milfont, "The use and abuse of the new environmental paradigm scale over the last 30 years: A metaanalysis," Journal of Environmental Psychology, vol. 30, pp. 143158, June 2010.

[12] M. Wisemana and F. X. Bogner, "A higher-order model of ecological values and its relationship to personality," Personality and Individual Differences, vol. 34, pp. 783-794, April 2003.

[13] L. Guttman, "A generalized nonmetric technique for finding the smallest coordinate space for a configuration of points," Psychometrika, vol. 33, pp. 469-506, December 1968

[14] S. Shye, D. Elizur, and M. Hoffman, Introduction to Facet Theory, Thousand Oaks, CA: Sage, 1994, pp. 106-127.

[15] J. A. Harkness and A. Schoua-glusberg, "Questionnaires in Translation," Zuma Nachrichten Spezial, vol. 3, pp. 87-126, 1998.

[16] J. P. Reser, N. Pidgeon, and A. Spence, Public Risk Perceptions, Understandings, and Responses to Climate Change in Australia and Great Britain: Interim Report, Griffith University, Climate Change Response Program, Queensland, Australia, and Understanding Risk Centre, Cardiff University, Wales, 2011.

[17] R. F. DeVellis, S. J. Blalock, K. Holt, B. R. Renner, L. W. Blanchard, and M. L. Klotz, "Arthritis Patients' Reactions to Unavoidable Social Comparisons," Personality Social Psychology Bulletin, vol. 17, no. 4, pp. 392-399, August 1991.

[18] H. F. Kaiser, "Directional statistical decisions," Psychological Review, vol. 67, no. 3, pp. 160-167, May 1960.

[19] R. E. Dunlap, "The new environmental paradigm scale: From marginality to worldwide use," The Journal of Environmental Education, vol. 40, no. 1, pp. 3-18, 2008

[20] D. C. Pirages and P. R. Ehrlich, Ark II: Social Responses to Environmental Imperatives, San Francisco: W. H. Freeman, 1974

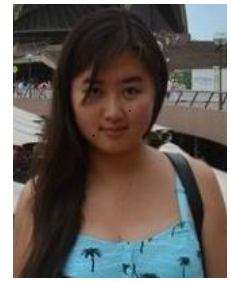

Wen Xue was born in Guiyang, China in 1986. She received the B.S. degree in electronic science and technique from the Department of Electronics and Physics in Hubei University, Wuhan, China in 2008, and the M.S. degree in applied psychology from the Department of Educational Science in Guizhou Normal University, Guiyang, China in 2011. From 2011 to now, she is with the School of Behavioural, Cognitive and Social Sciences in University of New England, Armidale, Australia as a Ph.D. student, researching on the environmental psychology.

Her specific research interest nowadays is in study environment psychology. In this research, environment problem, social psychology, and statistical methods are all involved. She is having engaged in the study of both social psychology and psychological methodology.

Dr. Xue is a student member of the Chinese Psychological Society. She has involved many projects, such as armidale house gas emission project, air pollution and hospital admissions project, household wood smoke project, alcohol/risky sex project, psychological development feature project for Chinese Children and Adolescents, China-UK Southwest Basic Education Project and so on. She has authored or co-authored more than 15 papers.

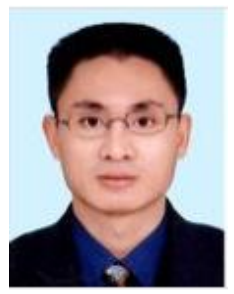

Shouying Zhao was born in Shandong, China in 1968. He received the B.S. degree in University of Petrolum, Beijing, China in 1989, and the M.S. degree in basic psychology in Guizhou Normal University, Guiyang, China in 2000. He received the Ph.D. degree in psychometrics in Beijing Normal University, Beijing, China in 2004

Now, professor Zhao is the dean of the Department Educational Science in Guizhou Normal University, and also the vice-president of Guizhou Normal University. His current research interests include basic psychology, psychometrics, psychological research methods, psychological health and education. In 2006, he was a visiting scholar in the University of Manchester and got a master degree.

Prof. Zhao is a member of the Chinese Psychological Society. He received the first prize in the eighth of higher education in Guizhou provincial teaching achievement prizes. In 2002, He got a Swiss jacopo youth research projects. And since 2004, he hosted and participated in many subjects. He has authored or co-authored more than 100 papers. 